\title{
Corrigendum to "Effect of Inhalation of Aromatherapy Oil on Patients with Perennial Allergic Rhinitis: A Randomized Controlled Trial"
}

\author{
Seo Yeon Choi and Kyungsook Park \\ Department of Nursing, College of Nursing, Chung-Ang University, 84 Heukseok-ro, Dongjak-gu, Seoul 156-756, Republic of Korea \\ Correspondence should be addressed to Kyungsook Park; kspark@cau.ac.kr
}

Received 9 August 2016; Accepted 22 August 2016

Copyright (C) 2016 S. Y. Choi and K. Park. This is an open access article distributed under the Creative Commons Attribution License, which permits unrestricted use, distribution, and reproduction in any medium, provided the original work is properly cited.

In the article titled "Effect of Inhalation of Aromatherapy Oil on Patients with Perennial Allergic Rhinitis: A Randomized Controlled Trial," [1] there were some errors that should be corrected as follows.

In the abstract section "geranium" should be changed to "frankincense." Also, the Latin botanical names of the three essential oils should have been presented as Santalum album (Sandalwood), Ravensara aromatica (Ravensara), and Boswellia carterii (Frankincense).

The authors confirm using "Ravensara" essential oil, rather than the similarly named "ravintsara."

\section{References}

[1] S. Y. Choi and K. Park, "Effect of inhalation of aromatherapy oil on patients with perennial allergic rhinitis: a randomized controlled trial," Evidence-Based Complementary and Alternative Medicine, vol. 2016, Article ID 7896081, 7 pages, 2016. 


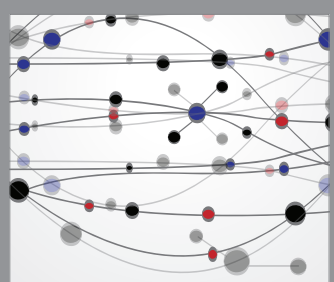

The Scientific World Journal
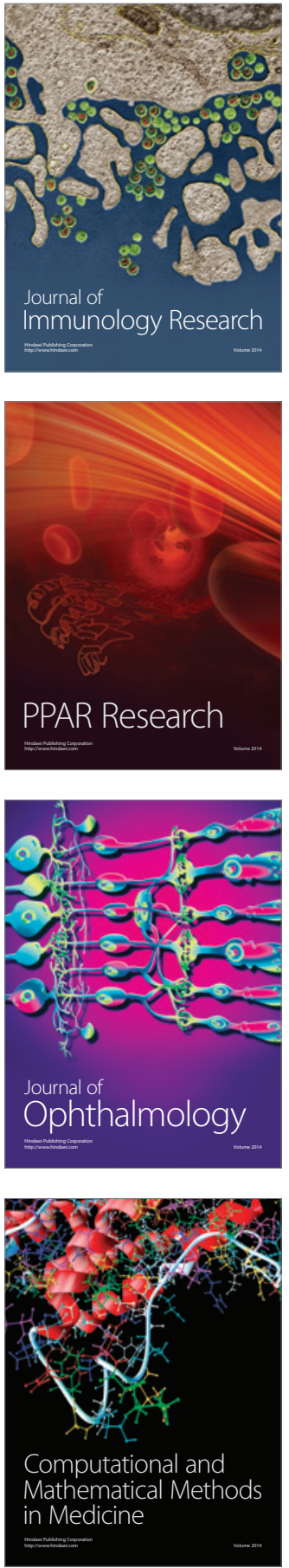

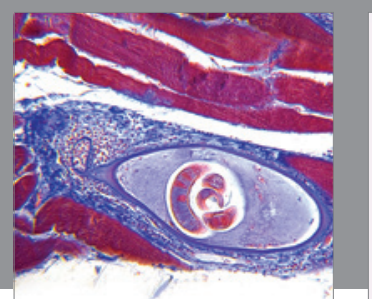

Gastroenterology Research and Practice

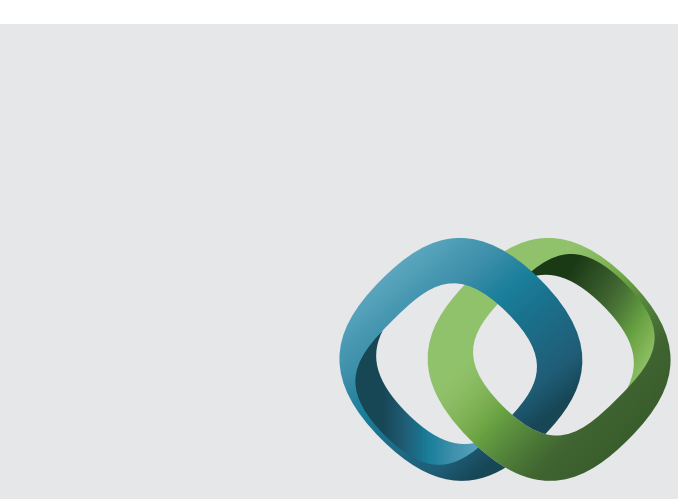

\section{Hindawi}

Submit your manuscripts at

http://www.hindawi.com
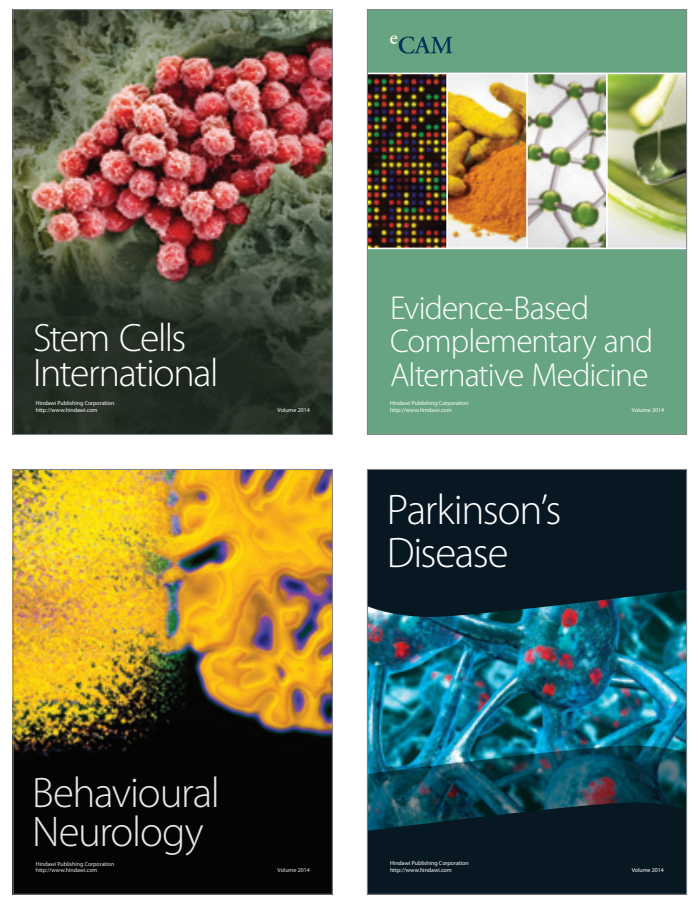
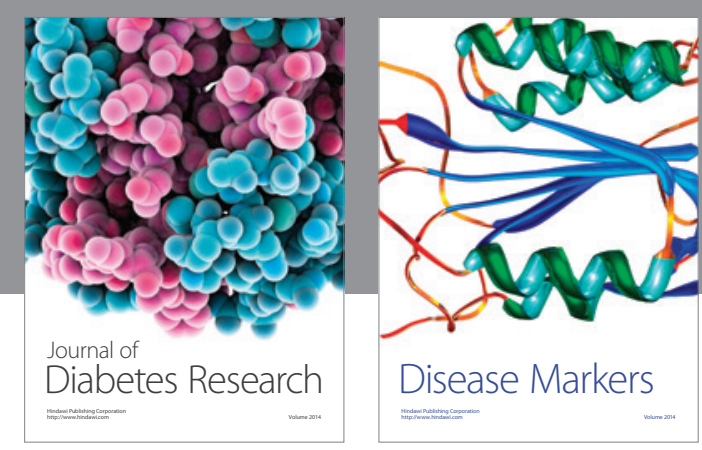

Disease Markers
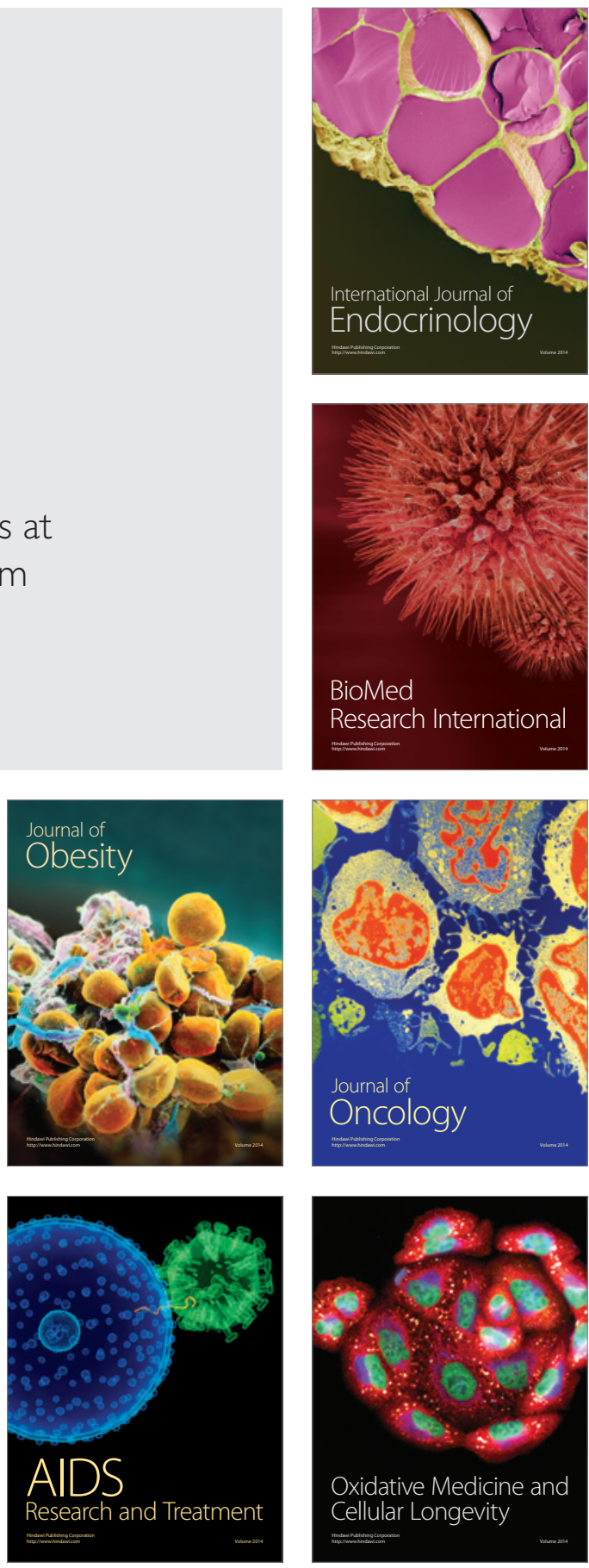